\title{
Une représentation à Compiègne de Pierre le Grand, opéra révolutionnaire d'A.M. Grétry (1790)
}

Jacques Bernet

\section{(2) OpenEdition \\ 12 Journals}

Édition électronique

URL : https://journals.openedition.org/ahrf/3683

DOI : $10.4000 /$ ahrf.3683

ISSN : 1952-403X

\section{Éditeur :}

Armand Colin, Société des études robespierristes

\section{Édition imprimée}

Date de publication : 1 septembre 2002

Pagination : 169-172

ISSN : 0003-4436

\section{Référence électronique}

Jacques Bernet, « Une représentation à Compiègne de Pierre le Grand, opéra révolutionnaire d'A.M.

Grétry (1790) ", Annales historiques de la Révolution française [En ligne], 329 | juillet-septembre 2002, mis en ligne le 27 mars 2008, consulté le 23 avril 2022. URL : http://journals.openedition.org/ahrf/ 3683 ; DOI : https://doi.org/10.4000/ahrf.3683 


\title{
POINT DE VUE
}

\section{UNE REPRÉSENTATION À COMPIÈGNE DE PIERRE LE GRAND, OPÉRA RÉVOLUTIONNAIRE D’A.M. GRÉTRY (1790)}

\author{
JACQUES BERNET
}

Pour le dixième anniversaire de la résurrection du Thêâtre impérial de Compiègne (1), le Théâtre français de la Musique animé par le metteur en scène Pierre Jourdan et qui y a son siège, a eu l'heureuse initiative de remonter Pierre le Grand, une ouvre tardive sinon majeure de Grétry (1741-1813), d'autant plus méconnue de nos jours qu'à notre connaissance cet opéra-comique, créé à Paris en janvier 1790 par la Comédie-Italienne, n'avait pas été rejoué sur une scène française depuis 1817 (2). Située dans l'œuvre prolifique du compositeur liégeois entre l'opéra néo-médiéval Raoul Barbe-Bleue (mars 1789) et le «drame» historique Guillaume Tell (avril 1791), Pierre le Grand, "comédie " en 3 actes, appartient à la dernière période dramatique et musicale de Grétry, coïncidant avec la décennie révolutionnaire, au cours de laquelle le vieux maitre dut et sut s'adapter tant bien que mal au nouveau cours politique (3). Certes cette période finale

(1) Construite par Napoléon III pour la Cour lors de ses séjours au château de Compiègne, cette salle à l'italienne, inspirée de l'opéra de Versailles, n'était pas tout à fait terminée au moment de la chute de l'Empire; elle a été entièrement réaménagée et inaugurée à l'automne 1991.

(2) D'après David ChaRLTon, Grétry and the growth of opera-comique, Cambridge University Press, 1986, p. 298.

(3) Sur cette période difficile de la vie d'A.M. Grétry (1741-1813), cf. l'importante étude d'Elizabeth C. BARTLET, "Grétry and the Revolution ", dans Grétry et l'Europe de l'opéra-comique, Mardaga, Liège, 1992, pp. 47-110. L'auteur, qui s'intéresse essentiellement à la carrière et l'œuvre du compositeur de 1792 à

Annales historiques de la Révolution française - 2002 - N 3 [169 à 172] 
n'est sans doute pas la plus réussie et la plus féconde de sa longue carrière artistique, mais elle n'en est pas moins significative au plan historique et esthétique, puisqu'elle reflète assez bien l'évolution de la scène et de la musique en France au choc des événements révolutionnaires (4).

Le livret du jeune Jean-Nicolas Bouilly (1763-1842), son premier ouvrage proposé pour la scène musicale, en juillet 1789 , était fort librement inspiré de Voltaire (Le siècle de Louis XIV, L'Histoire de Charles XII et une Histoire de Russie sous Pierre le Grand publiée en 1760). Lauteur avait de toute évidence complètement idéalisé la jeunesse et le caractère du tsar modernisateur de la Russie, fondateur de Saint-Petersbourg, de manière à en faire un modèle de souverain éclairé proche de son peuple, dans lequel le public français pourrait retrouver la figure d'un Louis XVI «paternel» et mythifié de la première année de la Révolution. Chargé de mettre l'œuvre en musique par la Comédie Italienne, Grétry, qui avait probablement à faire oublier ses compromissions avec la Cour (5), renforce encore la mystification dans l'avant-propos précédant l'édition de l'ouvrage en 1790: "Frappé d'étonnement et d'admiration à la vue de la régénération de la France, j'ai cherché dans l'histoire quelque trait qui y eût rapport, et que je puisse mettre en scène. J'ai vu qu'en Russie, Pierre le Grand avait dédaigné l'éclat et les délices $d u$ Trône pour se livrer entièrement au bonheur de ses peuples, comme Louis XVI le fait aujourd'hui pour le bonheur des Français. D'une multitude de Barbares sans mours, sans principes et sans talents, Pierre Alexiowitz en forma une société d'hommes instruits et policés; en appelant les Français à la participation des droits de la Royauté, Louis en fait un peuple de rois dont il devient le Dieu tulélaire. J'ai vu en outre le célèbre Lefort (6), Genevois, conduisant l'Empereur des Russes dans tout ce que ce Prince faisait de grand et mémorable; comme en France, Monsieur Necker dirige et seconde les vues bienfaisantes du Monarque. L'analogie est frappante. Aussi personne ne s'y est trompée, et j'ai eu la douce satisfaction de voir éclater dans tous les coeurs l'amour, le respect et la fidélité, sentiments dont je suis intimement pénétré pour ma Patrie et pour mon Roi.» (7)

1797, montre comment le musicien longtemps attaché à la Cour put s'adapter au nouveau cours politique, à la fois par opportunisme et pour des raisons financières. Patriote très modéré, âgé et affecté par les deuils familiaux, Grétry ne retrouva une réelle stabilité que sous le Consulat, grâce à la faveur de Bonaparte qui aimait beaucoup sa musique.

(4) Cf. Michelle BIGET (dir.), Vie musicale et courants de pensée, 1780-1830, Actes du colloque de Rouen, octobre 1986, Institut de Musicologie de Rouen, 1988, 225 p.

(5) Le compositeur liégeois avait créé plusieurs de ses opéras à Versailles et dirigé la musique de Marie-Antoinette, qui l'appréciait beaucoup. Sous la Révolution, le fameux air de Richard Cour de Lion (1783), « O Richard, ô mon Roi », devint l'hymne favori des royalistes.

(6) Ce personnage, présenté comme l'ami et le premier conseiller de Pierre le Grand résidant incognito en Courlande, est en effet avec Pierre et Catherine, un des principaux protagonistes de l'œuvre de Bouilly et Grétry.

(7) L'opéra se termine en effet par un tableau où est rendu un hommage explicite à Louis XVI, ce qui ne manqua pas de susciter quelques polémiques au moment de la sortie de l'ouvrage. 
De fait l'ouvrage de Bouilly et Grétry prenait de larges libertés avec l'histoire, confondant allégrement la jeunesse de Pierre en Courlande avec ses séjours incognito sous l'habit d'un noble russe en Europe occidentale, ou encore transformant la rencontre avec Catherine, que le tsar épousa après avoir répudié sa première femme, en une bluette sentimentale entre un prince et une jeune bergère, dans le plus pur style de l'époque... Mais peu importe, c'est précisément ce travestissement historique qui est politiquement intéressant et très révélateur des circonstances de l'œuvre. Par ailleurs la musique de Grétry, sans toujours atteindre la qualité de ses chefs-d'œuvre de la maturité, Zémire et Azor, l'Amant jaloux, le jugement de Midas ou Richard Couur de lion, y est fort gracieuse, déployant généralement toutes les ressources de sa riche invention mélodique et de son profond sens dramatique. Si quelques chœurs, comme celui du finale, s'appuyant sur des textes médiocres, sont un peu pompeux et vieillis, on trouve de magnifiques solos et duos de Pierre (ténor), François Lefort (baryton) et surtout de Catherine (soprano), ainsi que des ensembles vocaux et orchestraux particulièrement réussis. Comme dans $L a$ Caravane du Caire, où Grétry s'était essayé à la couleur orientale, ou dans les opéras néo-gothiques (Richard, Raoul, le Comte Albert), le compositeur liégeois a tenté avec plus ou moins de bonheur d'apporter une touche exotique locale, en orchestrant un pas de danse réputé venir de Russie... L'interprétation qui nous a été proposée à Compiègne par Olivier Opdebeeck, à la tête des chœurs de Namur et de l'orchestre de Chambre de Wallonie qu'il dirige, réduit ici à une moyenne formation de onze musiciens (8), avec d'excellents solistes (9), était de grande qualité du point de vue des sonorités et des tempos, s'appuyant sur un excellent travail de restitution de la partition d'origine (10).

Il est d'autant plus dommage que le metteur en scène Pierre Jourdan ait cru nécessaire de remplacer les dialogues parlés de l'époque par un texte entièrement réécrit par Jean-Loup Horwitz, dit par un récitant affublé du titre grotesque de Commissaire du Peuple - correspondant bien davantage à la Révolution russe de 1917 qu'à la française de 1789 ! Ce factum balourd, bourré d'anachronismes et d'erreurs historiques grossières, fruit de l'imagination quelque peu délirante de ses auteurs, ne nous éclaire assurément pas sur le sens de l'opéra du maître liégeois : il contribue au contraire à l'obscurcir complètement, en nous faisant croire abusivement qu'il exprime une exacte vérité historique ! Autant dire que ces malheureux

(8) Huit cordes et trois instruments à vent. L'orchestre de la Comédie-Italienne à Paris à la fin du XVIII ${ }^{e}$ siècle comprenait en moyenne 17 à 19 instrumentistes.

(9) Catherine, interprétée par la soprano Anne-Sophie Schmidt, Pierre le Grand par le ténor Christophe Einhorn, François Lefort par le baryton Philippe Le Chevalier, Georges par la basse Eick Freulon, pour s'en tenir aux principaux rôles.

(10) Comme pour tous les opéras de cette époque, il existait plusieurs versions successives : Grétry avait d'ailleurs réduit l'œuvre de quatre à trois actes. 
ajouts irritent au plus haut point les spectateurs, en défigurant gravement l'ouvrage de Bouilly et Grétry. Espérons à tout le moins que nous pourrons prochainement disposer d'une version en compact, avec les mêmes interprètes musicaux, mais débarrassée de tout ce qui l'encombre et la déforme bien inutilement. 